\title{
RESENHA
}

\section{A EPIDEMIA DE DIAGNÓSTICOS E A MEDICALIZAÇÃO DA EDUCAÇÃO: desafios à formação e atuação docentes.}

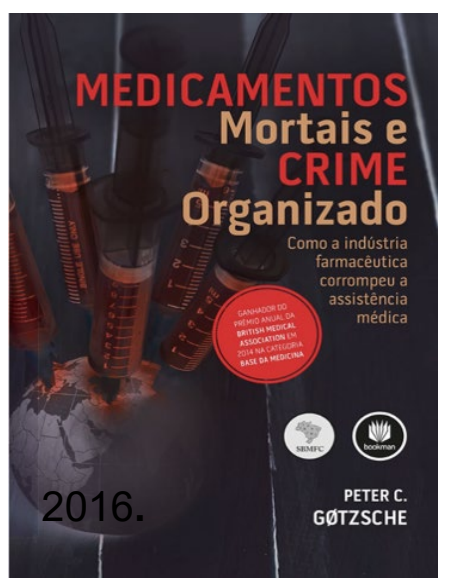

Por Dyego Oliveira da Silva Centro Universitário Fluminense (UNIFLU) Campos dos Goytacazes, RJ, Brasil GØTZSCHE, Peter C. Medicamentos mortais e crime organizado: como a indústria farmacêutica corrompeu a assistência médica. Tradução: Ananyr Fajardo. Porto Alegre: Bookman, 2016.

DOI: https://doi.org/10.22409/mov.v7i15.42596

Dinamarquês e famoso por denunciar como a indústria farmacêutica corrompeu a assistência médica, Peter Gøtzsche é médico, pesquisador, cofundador da Cochrane Collaboration e ex-líder do Nordic Cochrane Center em Rigshospitalet. Nasceu em 1949, estudou ciências no Mestrado em Biologia e Química e tornou-se representante de vendas de medicamentos, chegando a gerência. Expulso das próprias instituições que ajudou a criar devido suas denúncias, fundou em 2019 o Instituto de Liberdade Científica.

Autor de livros como Rational diagnosis and treatment: evidence-based clinical decision-making (2007), Mammography screening: truth, lies and controversy (2012), Deadly medicines and organised crime: how big pharma has corrupted healthcare (2013) e Deadly psychiatry and Organised Denial (2015), construiu essa obra através de relatos, confissões e documentos, revelando os interesses da indústria farmacêutica, que aproveita a supremacia cultural médica e utiliza de seu discurso cientificista para tornar a sociedade um grande objeto 


\section{movim nto \\ revista de educação do \\ programa de pós-graduação \\ faculdade de educação \\ ano 7 - número 15 - 2020}

disciplinado, assumindo o biopoder sobre ela, como diz Foucault (2001), determinando seus comportamentos, o que é normal e o que é patológico.

O livro tem a apresentação do médico Daniel Knupp Augusto e uma reflexão do nefrologista Drummond Rennie, colaborador do The Journal of American Medical Association (JAMA), que expõe sua "indignação baseada em evidências". São 562 páginas (versão e-book) e 22 capítulos com títulos instigantes tentando convencer a não usarmos tantos medicamentos. Grandes nomes conhecidos mundialmente como a Hoffman-La Roche, Pfizer, Novartis, Sanofi-Aventis, GlaxoSmithKline, AstraZeneca, Roche, Johnson \& Johnson, Merck, Eli Lilly e Abbott estão na mira.

"Os medicamentos prescritos são a terceira causa de morte no mundo, depois das doenças cardíacas e do câncer" e ninguém faz nada. Existe um mercado, como o do tabaco que compra líderes de muitos setores. Mentiras são vendidas por mercenários para que o povo, enganado e confundido por falsos resultados, fornecidos pelos próprios fabricantes, comprados e anunciadas em todas as redes de comunicação, possa ser manipulado por interesses maiores que o cuidado sobre si e sobre o outro. É como pedir a um assassino corrupto que dê sua própria sentença em um tribunal.

Para quem não se conforma com o pseudofluxo natural das coisas, a "falha geral do sistema causada por crime disseminado, corrupção e regulação impotente de medicamentos" é exposta. Nas "Confissões de um informante", relatos concretos de mortes que ocorreram por inaladores para asma, o marketing disfarçado e as pesquisas duvidosas. "Crime organizado, o modelo de negócios das grandes empresas farmacêuticas" até chegar a "Rindo por último das grandes empresas farmacêuticas". Todos muito bem referenciados.

Gøtzsche não teve boas experiências com medicamentos ao vê-los destruindo seu avô no fim da vida. O marketing mentiroso vendia a resolução dos problemas num toque de mágica, como as pílulas citadas por Whitaker (2017), sem pensar nos malefícios. Pontes sendo construídas, conexões obscuramente acontecendo entre quem quer apenas vender (máfia farmacêutica) e quem administra tais drogas (médico). São cheques de alto valor, viagens, jantares 


\section{movim nto \\ revista de educação do \\ programa de pós-graduação \\ faculdade de educação \\ ano 7 - número 15 - 2020}

luxuosos e presentes. O resultado é novos "doentes". Surge uma nova quadrilha, a "BigPharma".

É assustador quantas similaridades existem entre essa indústria e as quadrilhas criminosas. As quadrilhas produzem quantidades obscenas do dinheiro, assim como essa indústria. Os efeitos colaterais do crime organizado são matanças e mortes, e os efeitos colaterais são os mesmos nessa indústria. As quadrilhas subornam políticos e outros, e assim faz a indústria farmacêutica (GØTZSCHE, 2016, p. 100).

O crime corporativo mata, lesa e rouba expressivos valores de dinheiro dos contribuintes. São crimes tão disseminados, que acontecem ciclicamente e de formas diversas, deliberadamente, que não resta outro pensamento a não ser: "o crime compensa". Aquele que se alia, carrega também sangue de muitos inocentes. Não importa se por armas ou comprimidos, vidas estão sendo ceifadas. O próprio Gøtzsche diz:

Quando um crime levou à morte milhares de pessoas, devemos encará-lo como um crime contra a humanidade. Não deve fazer diferença para nossa percepção de delito se foram mortos por armas ou por comprimidos (GØTZSCHE, 2016, p.101).

Além de experiências com seres humanos em muitas áreas, a psiquiatria se corrompe e substitui o cuidado pelo comprimido. A medicalização, o "fazer medicina", segundo Conrad (1992), veste novas roupas e processos não médicos são tidos como problemas médicos (CONRAD; SCHNEIDER, 1980). Repensemos. Blaxter (1978) olha de perto o diagnóstico e suas consequências e finalidades, sabendo que tal é entendido como categoria e processo, como uma ferramenta que produz lugares sociais importantes, marcando e estigmatizando o corpo, travestindo-o de diferença e inferioridade, como diz Goffman (1988).

"O pior de tudo isso era que os crimes atingiam em cheio também as crianças" e como Sanches e Amarante (2014) dizem, muitas têm problemas sociais e são encaminhadas a serviços médicos, de saúde mental, recebendo indicações de psicofármacos. Foucault (2001) reforça que desarticulando o sujeito de seu sofrimento, os sintomas assumem papel principal na determinação da doença, revelando uma patologia e não uma oportunidade de solução. O paciente se torna o que o outro vê e incide sobre ele. O cientificismo vendo o corpo como objeto, junto ao capitalismo e o poder do marketing, negam as individualidades de cada 


\section{movim nto \\ revista de educação do \\ programa de pós-graduação \\ faculdade de educação \\ ano 7 - número 15 - 2020}

sujeito e assumem seus sofrimentos como casos patológicos, medicando qualquer coisa.

Medicamentos administrados sem necessidade, em excesso e outros de forma clandestina arrastando as crianças (e adolescentes) a casos de risco de suicídio. O autor cita que em New Jersey, 1 em cada 30 meninos é diagnostico com Transtorno do Espectro Autista e cerca de um quarto de crianças em acampamentos de verão norte-americanos são medicados para transtorno de déficit de atenção e hiperatividade (TDAH), transtorno de humor ou outros problemas psiquiátricos. Mas vale lembrar que:

o fato de termos crianças sentadas quietas na escola não pode ser tomado como evidência de que o diagnóstico estava correto; mostra apenas que a anfetamina tem esse efeito (e muitos outros, incluindo apatia, falta de humor e isolamento social) (GØTZSCHE, 2016, p. 375).

Por isso hooks ${ }^{1}$ (2013) pensa o sujeito individualmente. O diagnóstico está além dos olhos de um terceiro, que incidem sobre o sujeito, em mais ou menos uma hora de conversa. Por isso o autor crê na necessidade de uma mudança cultural, onde os ensaios sejam um empreendimento público (e não feito pelas próprias empresas que fabricam os medicamentos), para o bem público e executados por instituições acadêmicas independentes. Enquanto isso, pensar medicalização da educação e práticas docentes, é saber que:

A educação está numa crise grave... Os educadores têm o dever de confrontar as parcialidades que tem moldado as práticas pedagógicas em nossa sociedade e criar novas maneiras de saber, estratégias diferentes para partilhar o conhecimento. Com estes ensaios, somo minha voz ao apelo coletivo pela renovação e pelo rejuvenescimento de nossas práticas de ensino. Pedindo a todos que abram a cabeça e o coração para conhecer o que está além das fronteiras do aceitável, celebro um ensino que permita as transgressões - um movimento contra as fronteiras e para além delas. É esse movimento que transforma e educação na prática da liberdade (HOOKS, 2018, p. 23-24).

Uau. O livro de Gøtzsche vem quebrar paradigmas e expor toda imundície escondida pelos ratos da máfia farmacêutica. Após essa leitura, fica a certeza a

\footnotetext{
1 Gloria Jean Watkins usava esse pseudônimo escrito em minúsculas porque seu objetivo era desafiar convenções linguísticas e acadêmicas, chamando atenção ao conteúdo de sua escrita e não à sua pessoa.
} 


\section{movim nto \\ revista de educação do \\ programa de pós-graduação \\ faculdade de educação ano 7 - número 15 - 2020}

você, leitor, que suas ideias não corresponderão mais aos fatos. Todos precisam beber dessa fonte de conhecimento. Sobretudo os profissionais da saúde. A vida alheia não é mais que dinheiro. O papel e o poder conscientizador que essa obra possui, são de longe, inigualáveis. Que se levantem mais "Gøtzsches", porque me desculpem a franqueza, "a gente não está com a bunda exposta na janela pra passar a mão nela" (GONZAGUINHA, 1988).

\section{Referências}

BLAXTER, Mildred. Diagnosis as Category and Process: The Case of Alcoholism. Social Science and Medicine. Social Science \& Medicine, n. 12, p. 9-17, 1978.

CONRAD, Peter. Medicalization and Social Control. Annual Review of Sociology: Palo Alto. v. 18, p. 209-232, 1992.

CONRAD, Peter; SCHNEIDER, Joseph. Looking at levels of medicalization: a comment of Strong's critique of the thesis of medical imperialism. Social Science \& Medicine, v. 14, 75-79, 1980.

FOUCAULT, Michel. O nascimento da clínica. Rio de Janeiro, RJ: Forense Universitária, 2001.

GOFFMAN, Erving. Estigma: notas sobre a manipulação da identidade deteriorada. Rio de Janeiro: LTC, 1988.

GONZAGUINHA. É. 1988.1 Disponível em: https://www.youtube.com/watch?v=Fwzc9CiyzqQ. Acesso em 30 de abril de 2020.

HOOKS, Bell. Ensinando a Transgredir: a educação como prática da liberdade. São Paulo: WMF Martins Fontes. 2a Edição, 2018.

SANCHES, Valéria Nogueira Leal; AMARANTE, Paulo Duarte de Carvalho. Estudo sobre o processo de medicalização de crianças no campo da saúde mental. Saúde em Debate, v. 38, n. 102, p. 506-514, 2014.

WHITAKER, Robert. Anatomia de uma epidemia: pílulas mágicas, drogas psiquiátricas e o aumento assombroso da doença mental. Rio de Janeiro: Fiocruz, 2017.

SOBRE O AUTOR 


\section{movim nto \\ revista de educação do \\ programa de pós-graduação \\ faculdade de educação \\ ano 7 - número 15 - 2020}

DYEGO OLIVEIRA DA SILVA é mestre em Ensino pela Universidade Federal Fluminense (UFF), professor do curso de Fonoaudiologia do Centro Universitário Fluminense (UNIFLU) e Diretor Clínico, de Pesquisa e Extensão do Instituto TEAmo, em Araruama, Rio de Janeiro.

E-mail: dyegoafonso@live.com

Recebido em: 06.05.2020

Aceito em: 24.05.2020 